\title{
Imaging the Folate Receptor on Cancer Cells with 99mTc-Etarfolatide: Properties, Clinical Use, and Future Potential of Folate Receptor Imaging
}

\author{
Alan H. Maurer ${ }^{1}$, Philip Elsinga ${ }^{2}$, Stefano Fanti ${ }^{3}$, Binh Nguyen ${ }^{4}$, Wim J.G. Oyen ${ }^{5}$, and Wolfgang A. Weber ${ }^{6}$ \\ ${ }^{1}$ Department of Radiology, Temple University Hospital and School of Medicine, Philadelphia, Pennsylvania; ${ }^{2}$ Department of Nuclear \\ Medicine and Molecular Imaging, University Medical Center Groningen, University of Groningen, Groningen, The Netherlands; \\ ${ }^{3}$ Department of Nuclear Medicine, Azienda Ospedaliero-Universitaria di Bologna, Policlinico S. Orsola-Malpighi, Bologna, Italy; ${ }^{4}$ Clinical \\ Development, Endocyte Inc., West Lafayette, Indiana; ${ }^{5}$ Department of Nuclear Medicine, Radboud University Nijmegen Medical Centre, \\ Nijmegen, The Netherlands; and ${ }^{6}$ Molecular Imaging and Therapy Service, Memorial Sloan-Kettering Cancer Center, New York, New York
}

\begin{abstract}
Folate receptor (FR) can be used as a therapeutic target because of its expression on different epithelial cancers, such as ovarian, nonsmall cell lung, endometrial, and breast cancer. Assessing FR expression in tumors may help to identify patients who can benefit from FR-targeted therapeutics, such as vintafolide and farletuzumab. Different methods exist to detect FR expression. Tissue sampling has limited clinical utility, mainly because it requires an invasive procedure. ${ }^{99 \mathrm{~m} T c-e t a r f o l a t i d e, ~ a ~}{ }^{99 \mathrm{~m} T c-l a b e l e d}$ folate conjugate, is in latephase trials in Europe and the United States. It allows noninvasive, whole-body imaging of the FR. This review focuses on this FRimaging agent and how it may be used to direct FR-targeted therapy.

Key Words: folate receptor; imaging; ${ }^{99 m} \mathrm{Tc}$-etarfolatide; SPECT; SPECT/CT
\end{abstract}

J Nucl Med 2014; 55:701-704

DOI: 10.2967/jnumed.113.133074

\section{FOLATE RECEPTOR AND CANCER}

Folate is a water-soluble B vitamin that is essential for cellular processes such as nucleotide biosynthesis (1). Cellular folate transport can be mediated by folate receptors (FRs), of which the $\alpha$ and $\beta$ subtypes are the most studied (2).

FR expression has been shown in varying levels in many epithelial tumors (3). Few nonmalignant tissues, such as epithelial cells in the kidney and placenta, show FR expression, as most cells use the reduced folate carrier for folate transport (4). For some tumors, such as ovarian cancer, FR expression is associated with tumor stage and grade and is a negative prognostic factor $(5,6)$. FRs are involved in tumor progression in various ways. First,

\footnotetext{
Received Mar. 13, 2014; revision accepted Mar. 17, 2014.

For correspondence or reprints contact: Alan H. Maurer, Department of Radiology, Section of Nuclear Medicine and Molecular Imaging, Temple University Hospital and School of Medicine, 3401 N. Broad St., Philadelphia, PA 19140.

E-mail: a.maurer@temple.edu

Published online Apr. 14, 2014.

COPYRIGHT (c) 2014 by the Society of Nuclear Medicine and Molecular Imaging, Inc.
}

the fact that FRs transport folate into cells appears to support proliferation of malignant cells (7). Second, FR expression was found to be associated with chemotherapy resistance in ovarian cancer, potentially by mediating apoptosis resistance $(6)$. Third, FR expression seems to support cell motility, as its expression in ovarian cancer is associated with downregulated E-cadherin expression (7).

Targeting of FR is an attractive anticancer treatment with limited toxicity. Different treatments targeting the FR have been developed, such as farletuzumab, vintafolide, EC1456 (a folatetubulysin conjugate in phase 1 trials), and IMGN853 (an anti-FR antibody-maytansinoid conjugate in phase 1 trials) (8). Farletuzumab and vintafolide have shown clinical promise in phase 2 and 3 trials $(3,9)$. Farletuzumab is an FR $\alpha$-specific monoclonal antibody that can induce cell death through complement-dependent cytotoxicity and antibody-dependent cell-mediated cytotoxicity (9). Vintafolide can deliver chemotherapy to FR-expressing cells, as it is a conjugate of folate and the chemotherapeutic agent desacetylvinblastine monohydrazide (3).

Because activated macrophages express FR $\beta$, targeting FR may also be effective in treatment of inflammatory diseases, such as rheumatoid arthritis and osteoarthritis $(8,10)$.

\section{FR EXPRESSION ASSESSMENT}

Assessing tumor FR expression can be both a prognostic and a diagnostic tool. Several methods have been used for FR detection, such as immunohistochemistry, polymerase chain reaction, quantitation polymerase chain reaction, or in situ hybridization $(5,6)$. Although these methods can have high specificity and sensitivity, their clinical use requires a biopsy, typically taken only once of a single lesion. This gives an incomplete picture, as FR expression can be heterogeneous $(11,12)$.

This cellular heterogeneity can occur between the primary lesion and distant metastases and during tumor evolution due to therapeutic resistance (12), thus creating a challenge to providing an accurate assessment of the patient's FR status. Wholebody imaging using FR-radiolabeled conjugates can address this challenge by allowing noninvasive assessment of FR expression for multiple lesions and at different times $(3,4,13)$. Additionally, 
FR imaging using radiolabeled conjugates leads to visualization of all functional FRs and not only FR $\alpha$, a fact that is important because FR-targeted treatments need to be actively transported into the cell by functional FRs (of any isoform) (11).

Early studies of radiolabeled FR $\alpha$-specific antibody MOv18 demonstrated ability to visualize FR expression in pelvic tumors (14). More recent studies have focused on the radiolabeled conjugates ${ }^{111}$ In-DTPA-folate (15) and ${ }^{99 \mathrm{~m}}$ Tc-etarfolatide (11).

\section{MTC-ETARFOLATIDE CHARACTERISTICS}

${ }^{99 m}$ Tc-etarfolatide takes advantage of the more optimal SPECT imaging characteristics of technetium (half-life of $6 \mathrm{~h}$ and $140-\mathrm{keV}$ photon) and has been evaluated in several clinical trials $(1,3,11,13,16)$.

Preclinical studies showed that, compared with unmodified folate, ${ }^{99 \mathrm{~m}} \mathrm{Tc}$-etarfolatide has an affinity value for human FRs of 0.92 and a $3.2 \mathrm{nM}$ dissociation constant, making ${ }^{99 \mathrm{~m}}$ Tc-etarfolatide suitable to visualize FR expression with high selectivity $(17,18)$. The radiation dosimetry estimates of ${ }^{99 \mathrm{~m}} \mathrm{Tc}$-etarfolatide are similar to those of other ${ }^{99 \mathrm{~m}} \mathrm{Tc}$ agents (average effective dose, 0.011 $\mathrm{mSv} / \mathrm{MBq}$ ), with the highest estimated doses being to the kidneys and urinary bladder wall (11). A 2-compartment pharmacokinetic model demonstrated rapid urinary and serum clearance, with relatively slow $99 \mathrm{~m}$ Tc-etarfolatide distribution from peripheral tissues into blood (11).

\section{MTC-ETARFOLATIDE IN CLINICAL TRIALS}

${ }^{99 \mathrm{~m}} \mathrm{Tc}$-etarfolatide is being studied as a companion diagnostic imaging agent in multiple vintafolide clinical trials. To date, no safety concerns have been identified and the only ${ }^{99 \mathrm{~m}} \mathrm{Tc}-$ etarfolatide-related adverse events were lower abdominal pain,

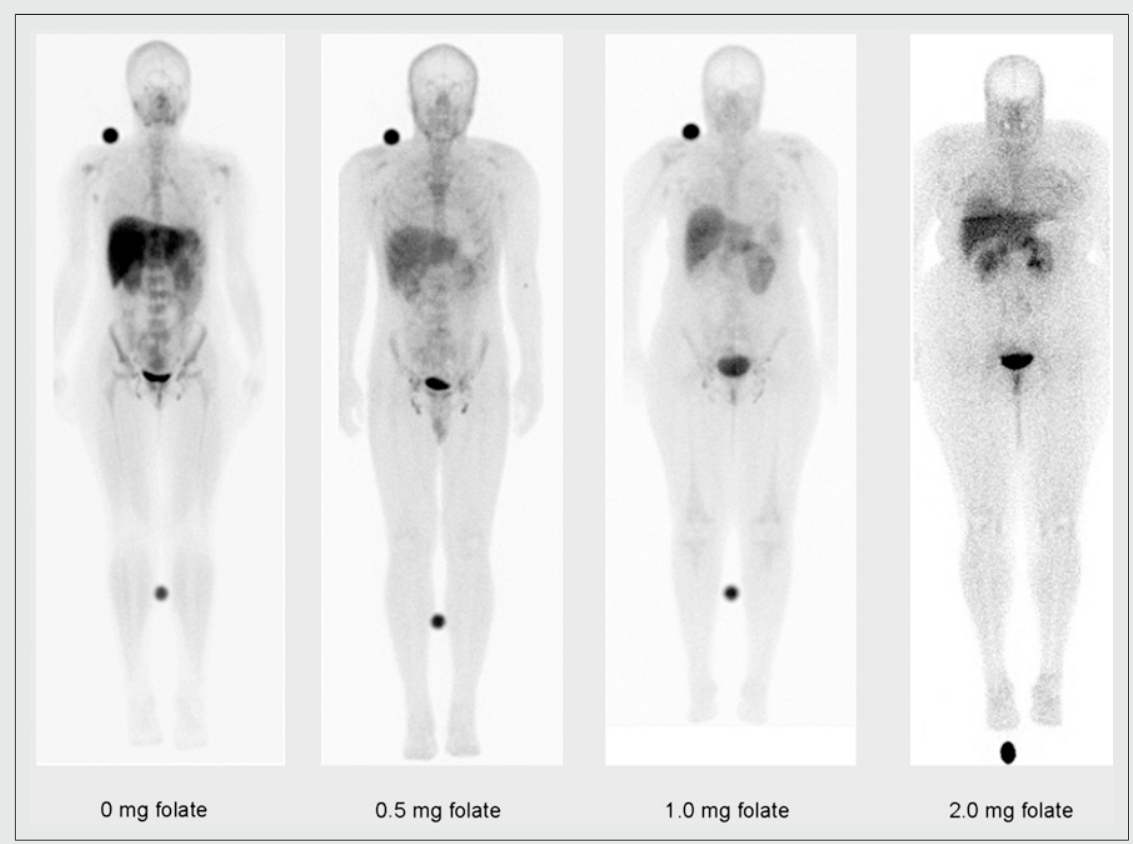

FIGURE 1. $99 \mathrm{~m} T \mathrm{Tc}$-etarfolatide biodistribution pattern ( $1 \mathrm{~h}$ after injection) after folate preinjection in healthy volunteers. In absence of folate preinjection, $99 \mathrm{mTc}$-etarfolatide uptake is seen in liver, kidney, spleen, bladder, and bone marrow. This background organ activity is decreased with preinjected folate. nausea, and vomiting (occurring in $<1 \%$ of patients) (11). Several phase 2 trials showed that ${ }^{99 \mathrm{~m}} \mathrm{Tc}$-etarfolatide imaging may be able to identify patients who are most likely to benefit from vintafolide $(3,13)$. In a phase 2 trial (NCT00507741) of single-arm vintafolide treatment, heavily pretreated patients with ovarian cancer were categorized as FR(100\%) if all evaluated lesions expressed FR $(n=14), \operatorname{FR}(10 \%-90 \%)$ if at least one but not all lesions expressed FR $(n=22)$, and FR( $0 \%)$ if no lesions expressed FR $(n=3)(13)$. The disease control rate (complete response + partial response + stable disease) was $57 \%$ in $\mathrm{FR}(100 \%)$ patients, compared with $36 \%$ and $33 \%$ in FR(10\%-90\%) and FR(0\%) patients, respectively. Median overall survival also correlated with FR expression: 14.6 mo in FR (100\%) patients, compared with 9.6 mo and 3.0 mo for FR (10\%-90\%) and FR(0\%) patients, respectively (13).

Additionally, a randomized phase 2 trial (PRECEDENT, NCT00722592) confirmed that ${ }^{99 \mathrm{~m}}$ Tc-etarfolatide imaging can identify patients likely to benefit from vintafolide. This trial compared the efficacy of vintafolide combined with pegylated liposomal doxorubicin (PLD; combination arm) with that of PLD alone (control arm) in patients with recurrent platinumresistant ovarian cancer (3). Median progression-free survival for $\operatorname{FR}(100) \%$ patients $(n=23)$ was 5.5 mo in the combination arm and $1.5 \mathrm{mo}$ in the control arm $(P=0.01)$, compared with 3.8 versus $5.4 \mathrm{mo}(P=0.468)$ for $\mathrm{FR}(0 \%)$ patients $(n=13)(3)$. The short progression-free survival of $\mathrm{FR}(100 \%)$ patients treated with PLD alone, compared with that of $\mathrm{FR}(0 \%)$ patients $(1.5$ mo vs. 5.4 mo, respectively), was suggestive of the potential tumor-promoting effects of FR. Furthermore, this phase 2 trial showed that FR(100\%) patients significantly benefited from the addition of vintafolide to PLD treatment. In line with the mechanism of action of vintafolide, the progression-free survival of $\mathrm{FR}(0 \%)$ patients was not significantly altered by combination treatment.

Several studies exploring the potential of 99m Tc-etarfolatide to assess FR2 expression are ongoing: a phase 3 trial (PROCEED, NCT01170650) in patients with 99mTcetarfolatide-positive platinum-resistant ovarian cancer treated with vintafolide combined with PLD versus PLD alone; a randomized phase 2 trial (TARGET, NCT01577654) in patients with ${ }^{99 \mathrm{~m} T c-e t a r f o l a t i d e-p o s i t i v e ~}$ lung cancer treated with vintafolide combined with docetaxel versus docetaxel alone versus vintafolide alone; and a phase 1 study (NCT01688791) in 99mTc-etarfolatide-positive patients with solid tumors for whom standard therapy has failed, assessing the maximum tolerated dose of vintafolide in combination with paclitaxel and carboplatin.

\section{MTC-ETARFOLATIDE IMAGING}

Although early clinical trials have suggested that ${ }^{99 \mathrm{~m}}$ Tc-etarfolatide imaging can be used to select patients who are likely to respond to vintafolide therapy, 


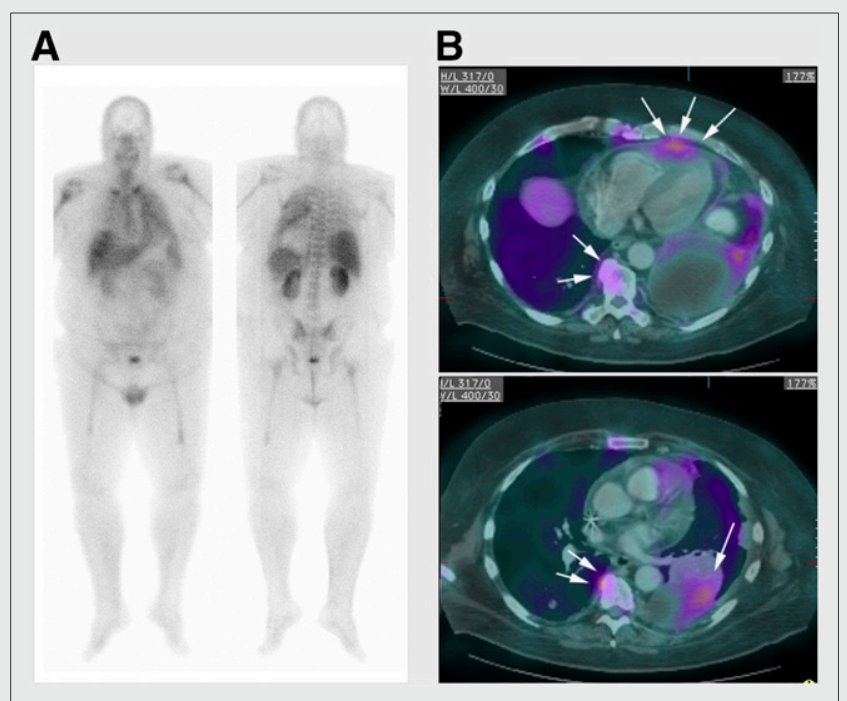

FIGURE 2. (A) Whole-body planar images obtained approximately $1 \mathrm{~h}$ after ${ }^{99 \mathrm{~m} T c}$-etarfolatide administration in lung cancer patient. (B) ${ }^{99 m T c}$-etarfolatide SPECT images were manually fused to patient's prior CT images. SPECT/CT transaxial fusion images delineate tumor in left lower lobe (single arrow), with diffuse pleural spread of tumor and pericardial metastasis (triple arrows). $99 \mathrm{mTc}$-etarfolatide uptake in inflammatory lesions such as benign osteophytes can be seen (double arrows).

there are both physiologic and technical factors that can affect imaging results and interpretation.

First, FR expression and ${ }^{99 m}$ Tc-etarfolatide physiologic uptake, which occurs in liver, kidneys, spleen, bladder, and, to a lesser extent, bone marrow, may complicate interpretation of FR expression in lesions close to these organs (11) (Fig. 1). To partially saturate FRs, and to reduce ${ }^{99 \mathrm{~m}} \mathrm{Tc}$-etarfolatide uptake in these organs, a small amount of folic acid is injected before ${ }^{99 \mathrm{~m}} \mathrm{Tc}-$ etarfolatide administration.

Because activated macrophages express FR $\beta$ and show up-

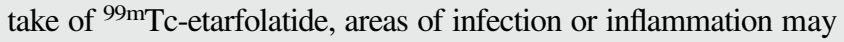
falsely appear as FR-positive malignant lesions $(8,19)$ (Fig. 2). Another FR-imaging agent, a conjugate of a reduced and alkylated form of folic acid $\left(N^{5}, N^{10}\right.$-dimethyltetrahydrofolic acid) and

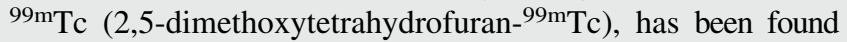
to more specially bind to $\mathrm{FR} \alpha$, which is often expressed on malignant cells, and less to FR $\beta$, often expressed by peripheral blood monocytes or inflammatory macrophages (20).

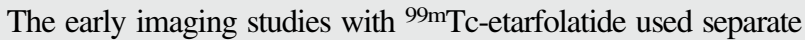
SPECT and CT images with only either visual side-by-side comparison or manual SPECT/CT fusion, because hybrid SPECT/CT cameras were not available. This technical limitation of using 2 noncontemporaneous studies may have limited these early studies. Integrated SPECT/CT cameras are becoming more prevalent. SPECT/CT fusion imaging should improve spatial localization and determination of FR-positive or -negative lesions (Figs. 2 and 3 ).

At present, limited data exist on the correlation between FR expression as assessed by immunohistochemistry and $99 \mathrm{~m} \mathrm{Tc}-$ etarfolatide uptake. One study showed a $61 \%$ agreement between methods ( $\kappa$ coefficient, 0.096 ; $95 \%$ confidence interval, -0.085 to 0.277 ) (11). The agreement was $72 \%$ for positive results and $38 \%$ for negative results ( ${ }^{99 \mathrm{~m}} \mathrm{Tc}$-etarfolatide-positive/-negative patients who are also FR immunohistochemistry-positive/-negative). These poor agreement scores could be related to tumor heterogeneity of FR expression, as immunohistochemistry analysis of primary tumors was compared with imaging of metastases (11). In addition, the immunohistochemistry did not identify FR $\beta$, whereas ${ }^{99 m}$ Tc-etarfolatide imaging does.

\section{PET FR IMAGING}

Folate can be labeled with ${ }^{18} \mathrm{~F}(21-25)$. To date, ${ }^{18} \mathrm{~F}$ fluorodeoxyglucose-folate and $3^{\prime}$-aza- $2^{\prime}-{ }^{18} \mathrm{~F}$-fluorofolic acid seem the most promising PET FR imaging agents. Both have shown good tumor visualization, with limited accumulation in nonmalignant tissues $(24,25) .{ }^{68} \mathrm{Ga}$-labeled radiofolates are also of interest because of their favorable biodistribution profile and 1 -step radiolabeling $(26,27)$. However, the short physical half-life of ${ }^{68} \mathrm{Ga}(68 \mathrm{~min})$ limits the time window for imaging compared with ${ }^{18} \mathrm{~F}$ (110 $\left.\mathrm{min}\right)(21)$. Although there are promising preclinical results, clinical studies of PET folate imaging agents are needed for their further development.

\section{POTENTIAL FUTURE APPLICATION OF 99MTC- ETARFOLATIDE IMAGING}

${ }^{99 m}$ Tc-etarfolatide imaging may have other clinical applications. Because FR expression is prognostic for ovarian and lung cancer, ${ }^{99 \mathrm{~m}} \mathrm{Tc}$-etarfolatide imaging may be used as a prognostic tool $(6,28)$. Intraoperative FR imaging with optical probes can improve staging and facilitates cytoreductive surgery (29). ${ }^{99 m}$ Tc-etarfolatide imaging may aid in selecting patients for intraoperative fluorescence FR imaging and help to identify deepseated lesions that could be missed by intraoperative optical imaging because of limited signal penetration.

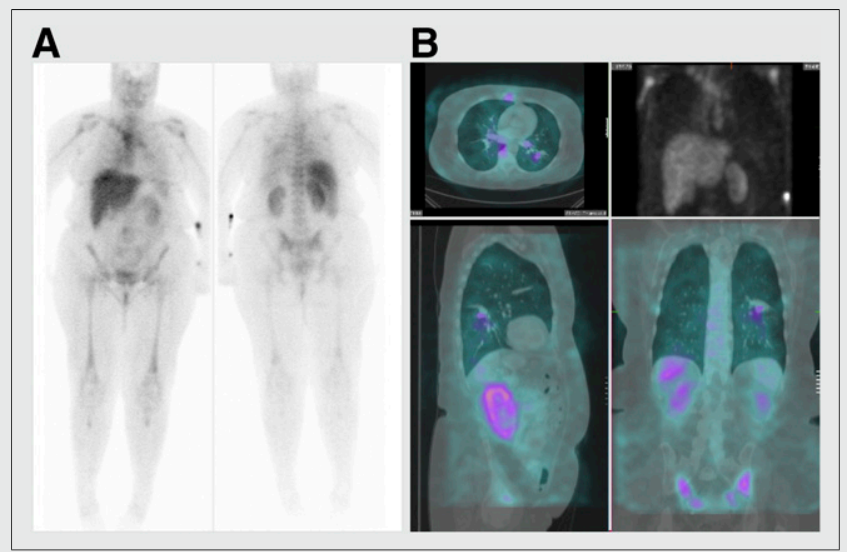

FIGURE 3. (A) Whole-body planar ${ }^{99 m}$ Tc-etarfolatide study for known pulmonary nodule obtained approximately $1 \mathrm{~h}$ after ${ }^{99 \mathrm{~m} T \mathrm{~T}-}$ etarfolatide administration. As with other imaging agents, planar 2-dimensional imaging lacks image contrast and sensitivity for detecting ${ }^{99 m}$ Tc-etarfolatide binding to small pulmonary nodule in

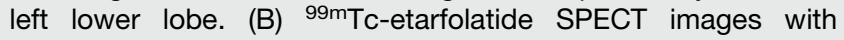
maximum intensity projection (upper right), transaxial (upper left), sagittal (lower left), and coronal (lower right) were manually fused to patient's prior CT images, allowing for better anatomic localization and confirmation of FR binding to pulmonary nodule in this biopsyproven non-small cell lung cancer. 
Preclinical studies have demonstrated that $99 \mathrm{~m}$ Tc-etarfolatide imaging can be used to visualize macrophage activation in atherosclerotic plaques and arthritis and to assess disease activity (30-32). One clinical study showed that ${ }^{99 \mathrm{~m}} \mathrm{Tc}$-etarfolatide imaging may be more sensitive than physical examination for assessing disease activity in rheumatoid arthritis patients (33). Other FRimaging agents have potential to visualize macrophage activation in osteoarthritis and atherosclerosis $(34,35)$.

\section{CONCLUSION}

${ }^{99 \mathrm{~m} T c-e t a r f o l a t i d e ~ i m a g i n g ~ h a s ~ b e e n ~ s h o w n ~ t o ~ b e ~ v a l u a b l e ~ f o r ~}$ selecting patients who may benefit from FR-targeted treatments. ${ }^{99 m}$ Tc-etarfolatide imaging may potentially also be useful for tumor staging or restaging, prognosis assessment, selection of patients for intraoperative fluorescence FR imaging, and assessment of inflammatory disease activity such as rheumatoid arthritis and osteoarthritis.

\section{DISCLOSURE}

Editorial and medical writing assistance (by Anna Hooijkaas, PhD, TRM Oncology, The Hague, The Netherlands) was funded by Endocyte Inc. Alan Maurer is a consultant and on the advisory board for Endocyte Inc. Philip Elsinga is a consultant for MSD. Stefano Fanti is on the advisory board for Endocyte Inc. Binh Nguyen is an employee of Endocyte Inc. Wim Oyen is a consultant for MSD and on the advisory board for Endocyte Inc. Wolfgang Weber is on the advisory boards for Endocyte Inc. and MSD. No other potential conflict of interest relevant to this article was reported.

\section{REFERENCES}

1. Teng L, Xie J, Teng L, Lee RJ. Clinical translation of folate receptor-targeted therapeutics. Expert Opin Drug Deliv. 2012;9:901-908.

2. Elnakat H, Ratnam M. Distribution, functionality and gene regulation of folate receptor isoforms: implications in targeted therapy. Adv Drug Deliv Rev. 2004;56:1067-1084.

3. Naumann RW, Coleman RL, Burger RA, et al. PRECEDENT: a randomized phase II trial comparing vintafolide (EC145) and pegylated liposomal doxorubicin (PLD) in combination versus PLD alone in patients with platinum-resistant ovarian cancer. $J$ Clin Oncol. 2013:31:4400-4406.

4. Muller C, Schibli R. Folate-receptor targeted radionuclide imaging agents. In: Jackman AL, Leamon CP, eds. Targeted Drug Strategies for Cancer and Inflammation. New York, NY: Springer; 2011:65-92.

5. Kalli KR, Oberg AL, Keeney GL, et al. Folate receptor alpha as a tumor target in epithelial ovarian cancer. Gynecol Oncol. 2008;108:619-626.

6. Chen YL, Chang MC, Huang CY, et al. Serous ovarian carcinoma patients with high alpha-folate receptor had reducing survival and cytotoxic chemo-response. Mol Oncol. 2012;6:360-369.

7. Siu MK, Kong DS, Chan HY, et al. Paradoxical impact of two folate receptors, FR $\alpha$ and RFC, in ovarian cancer: effect on cell proliferation, invasion and clinical outcome. PLOS ONE. 2012;7:e47201.

8. Low PS, Henne WA, Doorneweerd DD. Discovery and development of folic-acidbased receptor targeting for imaging and therapy of cancer and inflammatory diseases. Acc Chem Res. 2008;41:120-129.

9. Armstrong DK, White AJ, Weil SC, Phillips M, Coleman RL. Farletuzumab (a monoclonal antibody against folate receptor alpha) in relapsed platinum-sensitive ovarian cancer. Gynecol Oncol. 2013;129:452-458.

10. Xia W, Hilgenbrink AR, Matteson EL, Lockwood MB, Cheng JX, Low PS. A functional folate receptor is induced during macrophage activation and can be used to target drugs to activated macrophages. Blood. 2009;113:438-446.
11. Fisher RE, Siegel BA, Edell SL, et al. Exploratory study of ${ }^{99 \mathrm{~m} T c-E C 20}$ imaging for identifying patients with folate receptor-positive solid tumors. J Nucl Med. 2008;49:899-906.

12. Almendro V, Marusyk A, Polyak K. Cellular heterogeneity and molecular evolution in cancer. Annu Rev Pathol. 2013;8:277-302.

13. Morris RT, Joyrich RN, Naumann RW, et al. Phase 2 study of treatment of advanced ovarian cancer with folate-receptor-targeted therapeutic (vintafolide) and companion SPECT-based imaging agent ( ${ }^{99 \mathrm{~m} T c-e t a r f o l a t i d e) . ~ A n n ~ O n c o l . ~ I n ~ p r e s s . ~}$

14. Buist MR, Kenemans $P$, den Hollander W, et al. Kinetics and tissue distribution of the radiolabeled chimeric monoclonal antibody MOv18 $\operatorname{IgG}$ and $\mathrm{F}\left(\mathrm{ab}^{\prime}\right) 2$ fragments in ovarian carcinoma patients. Cancer Res. 1993;53:5413-5418.

15. Siegel BA, Dehdashti F, Mutch DG, et al. Evaluation of ${ }^{111}$ In-DTPA-folate as a receptor-targeted diagnostic agent for ovarian cancer: initial clinical results. J Nucl Med. 2003;44:700-707.

16. Banerjee S, Pillai MR, Ramamoorthy N. Evolution of Tc-99m in diagnostic radiopharmaceuticals. Semin Nucl Med. 2001;31:260-277.

17. Leamon CP, Parker MA, Vlahov IR, et al. Synthesis and biological evaluation of EC20: a new folate-derived, ${ }^{99 m}$ Tc-based radiopharmaceutical. Bioconjug Chem. 2002;13:1200-1210.

18. Reddy JA, Xu LC, Parker N, Vetzel M, Leamon CP. Preclinical evaluation of ${ }^{99 m}$ TcEC20 for imaging folate receptor-positive tumors. J Nucl Med. 2004;45:857-866.

19. Henne WA, Rothenbuhler R, Ayala-Lopez W, Xia W, Varghese B, Low PS. Imaging sites of infection using a ${ }^{99 \mathrm{~m}}$ Tc-labeled folate conjugate targeted to folate receptor positive macrophages. Mol Pharm. 2012;9:1435-1440.

20. Vaitilingam B, Chelvam V, Kularatne SA, Poh S, Ayala-Lopez W, Low PS. A folate receptor- $\alpha$-specific ligand that targets cancer tissue and not sites of inflammation. J Nucl Med. 2012;53:1127-1134.

21. Müller C. Folate-based radiotracers for PET imaging: update and perspectives. Molecules. 2013;18:5005-5031.

22. Bettio A, Honer M, Müller C, et al. Synthesis and preclinical evaluation of a folic acid derivative labeled with ${ }^{18} \mathrm{~F}$ for PET imaging of folate receptor-positive tumors. J Nucl Med. 2006;47:1153-1160.

23. Ross TL, Honer M, Müller C, Groehn V, Schibli R, Ametamey SM. A new ${ }^{18} \mathrm{~F}-$ labeled folic acid derivative with improved properties for the PET imaging of folate receptor-positive tumors. $J$ Nucl Med. 2010;51:1756-1762.

24. Betzel T, Müller C, Groehn V, et al. Radiosynthesis and preclinical evaluation of 3'Aza- $2^{\prime}-\left[{ }^{18} \mathrm{~F}\right]$ fluorofolic acid: a novel PET radiotracer for folate receptor targeting. Bioconjug Chem. 2013;24:205-214.

25. Fischer CR, Müller C, Reber J, et al. $\left[{ }^{18} \mathrm{~F}\right]$ fluoro-deoxy-glucose folate: a novel PET radiotracer with improved in vivo properties for folate receptor targeting. Bioconjug Chem. 2012;23:805-813.

26. Fani M, Tamma ML, Nicolas GP, et al. In vivo imaging of folate receptor positive tumor xenografts using novel ${ }^{68}$ Ga-NODAGA-folate conjugates. Mol Pharm. 2012;9: 1136-1145.

27. Fani M, Wang X, Nicolas G, et al. Development of new folate-based PET radiotracers: preclinical evaluation of ${ }^{68} \mathrm{Ga}$-DOTA-folate conjugates. Eur J Nucl Med Mol Imaging. 2011;38:108-119.

28. O'Shannessy DJ, Yu G, Smale R, et al. Folate receptor alpha expression in lung cancer: diagnostic and prognostic significance. Oncotarget. 2012;3:414-425.

29. van Dam GM, Themelis G, Crane LM, et al. Intraoperative tumor-specific fluorescence imaging in ovarian cancer by folate receptor- $\alpha$ targeting: first in-human results. Nat Med. 2011;17:1315-1319.

30. Ayala-López W, Xia W, Varghese B, Low PS. Imaging of atherosclerosis in apoliprotein e knockout mice: targeting of a folate-conjugated radiopharmaceutical to activated macrophages. J Nucl Med. 2010;51:768-774.

31. Turk MJ, Breur GJ, Widmer WR, et al. Folate-targeted imaging of activated macrophages in rats with adjuvant-induced arthritis. Arthritis Rheum. 2002;46: 1947-1955.

32. Paulos CM, Turk MJ, Breur GJ, Low PS. Folate receptor-mediated targeting of therapeutic and imaging agents to activated macrophages in rheumatoid arthritis. Adv Drug Deliv Rev. 2004;56:1205-1217.

33. Matteson EL, Lowe VJ, Prendergast FG, et al. Assessment of disease activity in rheumatoid arthritis using a novel folate targeted radiopharmaceutical Folatescan. Clin Exp Rheumatol. 2009;27:253-259.

34. Piscaer TM, Müller C, Mindt TL, et al. Imaging of activated macrophages in experimental osteoarthritis using folate-targeted animal single-photon-emission computed tomography/computed tomography. Arthritis Rheum. 2011;63:18981907.

35. Winkel LC, Groen HC, van Thiel BS, et al. Folate receptor-targeted single-photon emission computed tomography/computed tomography to detect activated macrophages in atherosclerosis: can it distinguish vulnerable from stable atherosclerotic plaques? Mol Imaging. 2013;12:1-5. 